\title{
Single Pulse Avalanche Robustness and Repetitive Stress Ageing of SiC power MOSFETs
}

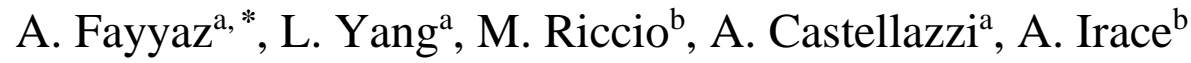 \\ ${ }^{a}$ Power Electronics, Machines and Control Group, University of Nottingham, Nottingham NG7 2RD, UK \\ ${ }^{\mathrm{b}}$ Dept. of Electrical Eng., University of Naples Federico II, Naples, Italy
}

\begin{abstract}
This paper presents an extensive electro-thermal characterisation of latest generation silicon carbide ( $\mathrm{SiC})$ Power MOSFETs under unclamped inductive switching (UIS) conditions. Tests are carried out to thoroughly understand the single pulse avalanche ruggedness limits of commercial SiC MOSFETs and assess their aging under repetitive stress conditions. Both a functional and a structural characterisation of the transistors is presented, with the aim of informing future device technology development for robust and reliable power system development.
\end{abstract}

\section{Introduction}

Silicon Carbide ( $\mathrm{SiC}$ ) power MOSFET fabrication technology has considerably matured over the recent years and therefore, they are now commercially available to buy in large quantities from various different manufacturers. SiC wide band-gap (WBG) power semiconductor devices including MOSFETs are by now a commercial reality $[1,2]$.

MOSFETs are widely used in high switching frequency applications and hence the assessment of their stability, robustness and reliability is vital for the development of high frequency switching power systems. Of particular importance is the assessment of the device ability to withstand avalanche breakdown regime. In high speed switching applications, back EMF (electromagnetic force) is produced during device turn-off due to the sudden change of current in inductive loads or parasitic elements which may force the MOSFET into drain-to-source avalanche and damage the device [3]. Avalanche ruggedness is an important asset for overall system robustness and enables competitive snubber-less designs.

The avalanche ruggedness of a device is usually assessed under the most rigorous test conditions, i.e. Unclamped Inductive Switching (UIS) conditions (see [4], for instance). Important performance indicators are the device ability to withstand single pulse energy dissipation and modifications in its characteristics as a result of repetitive stress applied. In this work, the capability of state-of-the-art commercially available $1200 \mathrm{~V} \mathrm{SiC}$ power MOSFETs to dissipate energy during avalanche breakdown under various single-pulse UIS test conditions was investigated and illustrated. The evolution of some critical parameters after repetitive UIS pulses, including gate-source threshold voltage $\left(\mathrm{V}_{\mathrm{th}}\right)$ and body diode forward voltage $\left(\mathrm{V}_{\mathrm{f}}\right)$, are also reported [5]. 


\section{Experimental results}

\subsection{Test Setup}

The schematics of a UIS test circuit is shown in Fig. 1. In order to avoid heating up the SiC MOSFET (DUT) before avalanche stress was applied, an auxiliary $3 \mathrm{kV}$ rated high voltage $\mathrm{Si}$ IGBT was connected in parallel to charge up the inductor current. A fixed $16 \mathrm{~V}$ gate signal was used to drive the IGBT.

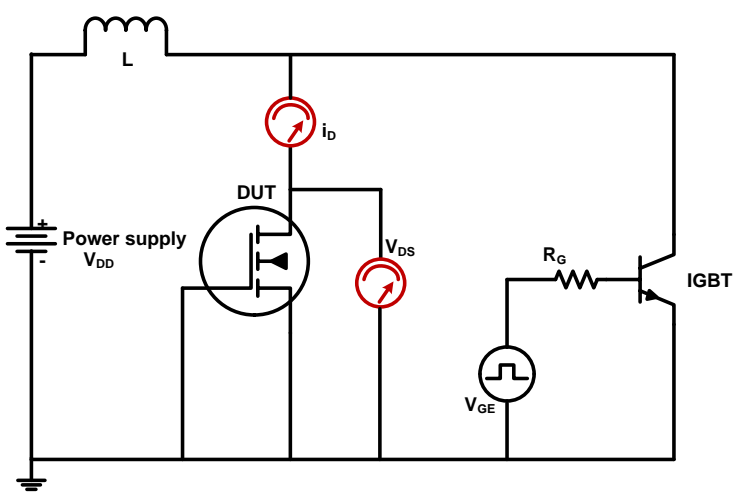

Fig. 1. UIS test circuit schematic

Fig. 2 shows the test circuit based on the circuit schematic in Fig. 1. In order to minimise stray inductance to avoid voltage overshoot, a double sided protoyping circuit board was used as a power plan and the use of wires were minimised by vertically mounting the gate driver directly. The overall capacitor bank is rated at $1.8 \mathrm{kV}$ to allow characterisation up to $1.8 \mathrm{kV}$. The DUT is mounted horizontally on a hotplate to allow characterisation at different case temperatures ( $\left.\mathrm{T}_{\mathrm{CASE}}\right)$ up to $200^{\circ} \mathrm{C}$. A high precision digital programmable signal generator was used to ensure fine control of the gate signal with resolution of $10 \mathrm{~ns}$.

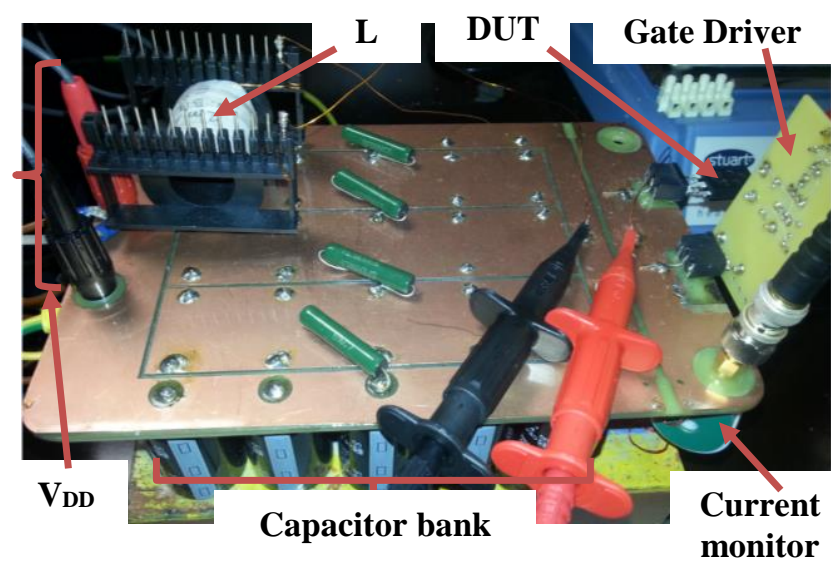

Fig. 2. UIS test circuit
The amount of energy dissipated by the devices during the time in avalanche, $\mathrm{t}_{\mathrm{AV}}$ can be derived by calculating the time integral of the product of the drainsource voltage $V_{D S}$ and the drain current $I_{D}$ :

$E_{A V}=\int_{t=0}^{t=t_{A V}} V_{D S}(t) \cdot I_{D}(t) d t$

Then, solving (1) for the time in avalanche yields:

$$
E_{A V}=\frac{1}{2} L I_{o}^{2} \cdot \frac{V_{B D(e f f)}}{V_{B D(e f f)}-V_{D D}}
$$

where $\mathrm{V}_{\mathrm{BD}(\mathrm{eff})}$ is the effective drain-source breakdown voltage during $\mathrm{t}_{\mathrm{AV}}$, which is not constant due to the thermal evolution of the device and $\mathrm{I}_{\mathrm{AV}}$ is the current at the start of the avalanche event.

Fig. 3 shows the typical set of waveforms for a non-destructive single-pulse UIS event: $\mathrm{V}_{\mathrm{GE}}$ is the gate signal applied to the IGBT (red); $\mathrm{I}_{\mathrm{L}}$ is the current in the inductor (green) and $\mathrm{V}_{\mathrm{DS}}$ is the voltage across the $\mathrm{SiC}$ MOSFET (blue). As can be seen, $\mathrm{V}_{\mathrm{DS}}$ is initially equal to $\mathrm{V}_{\mathrm{DD}}$ when device is OFF (In this study: $400 \mathrm{~V}$ and $800 \mathrm{~V}$ ) but reaches a breakdown value $\mathrm{V}_{\mathrm{BD} \text { (eff) }} \sim 1900 \mathrm{~V}$ during the UIS event. The actual breakdown voltage $\mathrm{V}_{\mathrm{BD}(\mathrm{eff})}$ is approximately $55-60 \%$ higher than the rated breakdown voltage $\mathrm{V}_{\mathrm{BD} \text { (DSS) }}$ of the device.

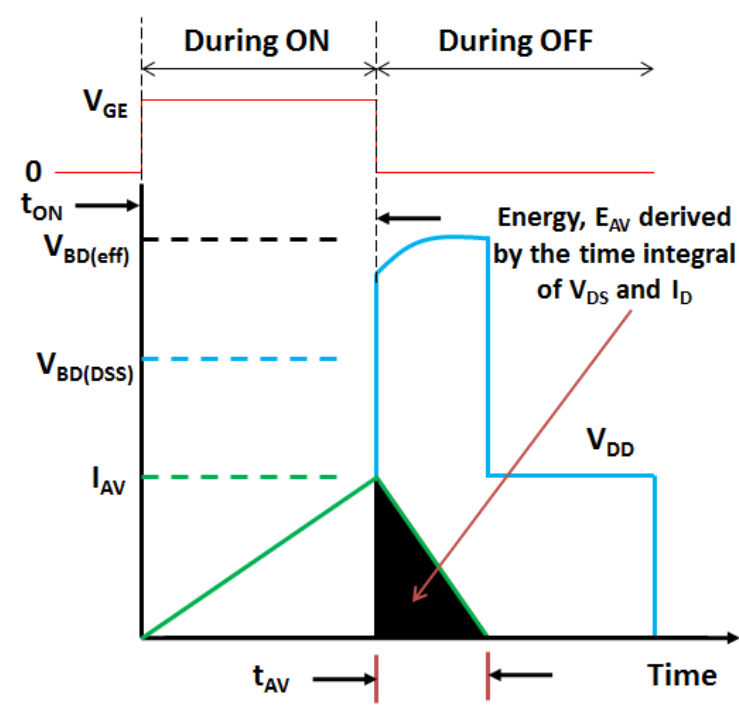

Fig. 3. Typical UIS test waveforms [4]

\subsection{Single pulse robustness test}

The main aim of this single pulse UIS test was to apply the same amount of $\mathrm{E}_{\mathrm{AV}}=1.2 \mathrm{~J}$ (ca. $55 \%$ of the device rated capability) by varying the rate of avalanche energy dissipation. Different inductance values along with adjustable gate drive pulse enabled 
to give different $\mathrm{I}_{\mathrm{AV}}$ and $\mathrm{t}_{\mathrm{AV}}$ values in order to obtain the same energy dissipation for all tests. Fig. 4 (a) and (b) show the current waveforms for $\mathrm{V}_{\mathrm{DD}}=400 \mathrm{~V}$ and at $\mathrm{T}_{\mathrm{CASE}}$ of $90^{\circ} \mathrm{C}$ and $150^{\circ} \mathrm{C}$ respectively.

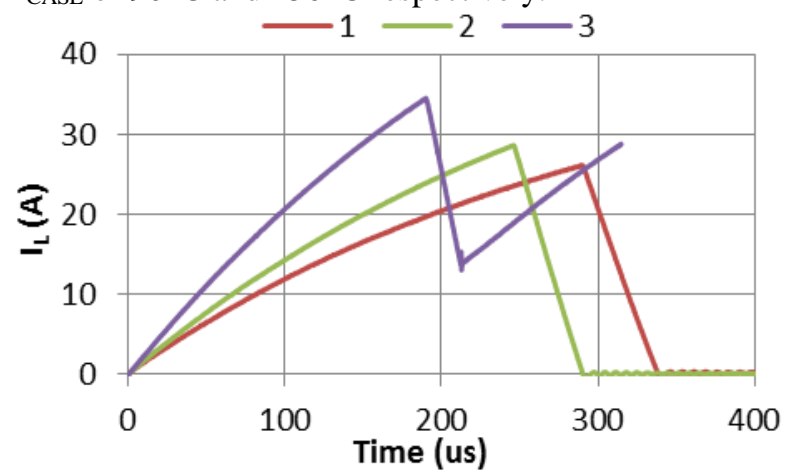

(a)

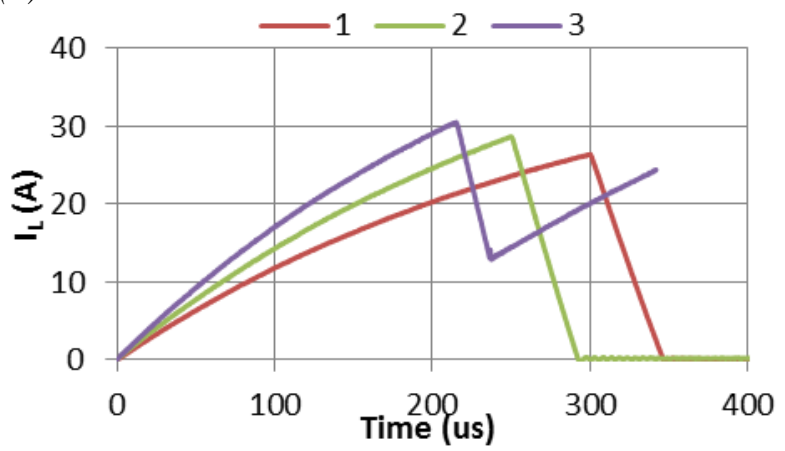

(b)

Fig. 4. Single pulse UIS waveforms at $T_{\text {CASE }}$ (a) $90^{\circ} \mathrm{C}$ and $(b) 150^{\circ} C, V_{D D}=400 \mathrm{~V}$ with various $L$ values and constant $E_{A V}$

The summarised test conditions for the tests corresponding to Fig. 4 (a) and (b) are summarised in Table 1 and 2 respectively.

Table 1 - Test Conditions summary for Fig. 4 (a) $V_{D D}=400 \mathrm{~V} ; T_{C A S E}=90^{\circ} \mathrm{C} ; E_{A V}=1.2 \mathrm{~J}$

\begin{tabular}{|l|l|l|l|l|l|}
\hline$\#$ & $\boldsymbol{I o}(\boldsymbol{A})$ & $\boldsymbol{L}(\boldsymbol{u H})$ & $\boldsymbol{V}_{\boldsymbol{B D}(\text { eff })}(\boldsymbol{V})$ & $\boldsymbol{t}_{\text {oN }}(\boldsymbol{u s})$ & $\boldsymbol{t}_{\boldsymbol{A} \boldsymbol{V}}(\boldsymbol{u s})$ \\
\hline 1 & 26.2 & 2765 & 1849 & 290 & 50 \\
\hline 2 & 28.7 & 2332 & 1855 & 246 & 46 \\
\hline $\mathbf{3}$ & $\mathbf{3 4 . 5}$ & $\mathbf{1 6 2 5}$ & $\mathbf{1 8 6 0}$ & $\mathbf{1 9 0}$ & $\mathbf{3 8 . 4}$ \\
\hline
\end{tabular}

Table 2 - Test Conditions summary for Fig. $4(b)$

$V_{D D}=400 \mathrm{~V} ; T_{C A S E}=150^{\circ} \mathrm{C} ; E_{A V}=1.2 \mathrm{~J}$

\begin{tabular}{|l|l|l|l|l|l|}
\hline \# & $\boldsymbol{I} \boldsymbol{o}(\boldsymbol{A})$ & $\boldsymbol{L}(\boldsymbol{u H})$ & $\boldsymbol{V}_{\boldsymbol{B D}(\text { eff })}(\boldsymbol{V})$ & $\boldsymbol{t}_{\text {ON }}(\boldsymbol{u} \boldsymbol{s})$ & $\boldsymbol{t}_{\boldsymbol{A V}}(\boldsymbol{u s})$ \\
\hline 1 & 26.5 & 2723 & 1900 & 300 & 47.7 \\
\hline 2 & 28.5 & 2316 & 1902 & 250 & 44 \\
\hline $\mathbf{3}$ & $\mathbf{3 0 . 5}$ & $\mathbf{1 8 7 6}$ & $\mathbf{1 9 0 6}$ & $\mathbf{2 1 5}$ & $\mathbf{3 8}$ \\
\hline
\end{tabular}

The current waveforms at $\mathrm{V}_{\mathrm{DD}}=800 \mathrm{~V}$ for 2 different
$\mathrm{T}_{\mathrm{CASE}}$ of $90^{\circ} \mathrm{C}$ and $150^{\circ} \mathrm{C}$ are shown in Fig. 5 (a) and (b) respectively.

Fig. 4 and 5 show that, even though the $E_{\mathrm{AV}}$ value was kept constant, transition from safe UIS to failure was caused by an increased power dissipation rate within the device. This demonstrates the fact that energy dissipation rate also play a role in determining the avalanche failure limits of power MOSFETs along with the $\mathrm{E}_{\mathrm{AV}}$ value [6]. It is an indication of thermally driven failure type, since the maximum $\mathrm{T}_{\mathrm{J}}$ increases as the power dissipation rate is increased [6].

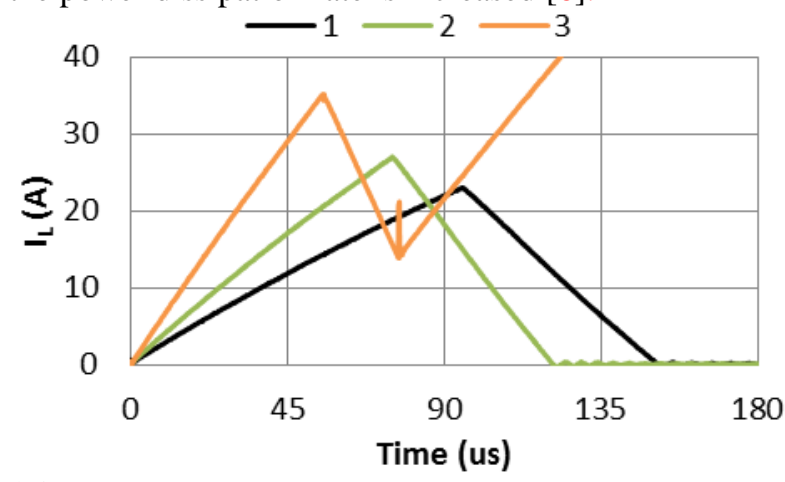

(a)

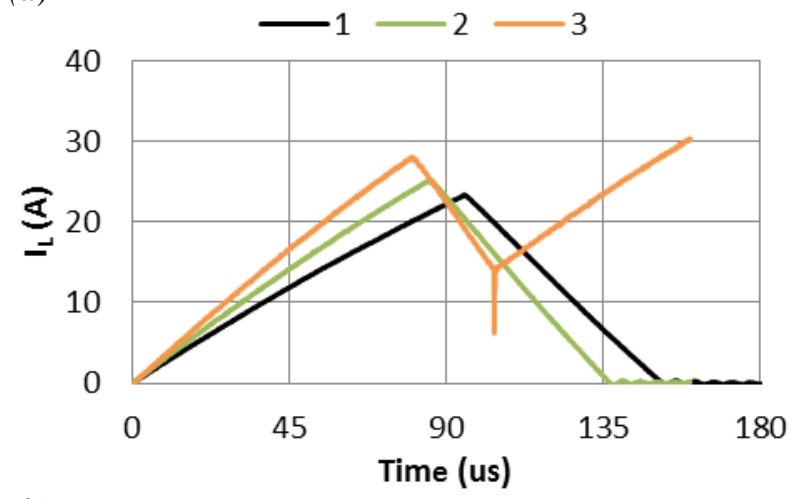

(b)

Fig. 5. Single pulse UIS waveforms at $T_{C A S E}$ (a) $90^{\circ} \mathrm{C}$ and (b) $150^{\circ} C, V_{D D}=800 \mathrm{~V}$ with various $L$ values and constant $E_{A V}$

The summarised test conditions for the tests corresponding to Fig. 5 (a) and (b) are summarised in Table 3 and 4 respectively.

Table 3 - Test Conditions summary for Fig. 5 (a)

\begin{tabular}{|c|c|c|c|c|c|}
\hline \multicolumn{6}{|c|}{$V_{D D}=800 \mathrm{~V} ; T_{C A S E}=90^{\circ} \mathrm{C} ; E_{A V}=1.2 \mathrm{~J}$} \\
\hline \# & Io $(A)$ & $L(u H)$ & $V_{B D(e f f)}(V)$ & ton (us) & $t_{A V}(u s)$ \\
\hline 1 & 23.0 & 2464 & 1881 & 95.2 & 56.3 \\
\hline 2 & 27.0 & 1885 & 1885 & 75.1 & 46.9 \\
\hline 3 & 35.2 & 1100 & 1894 & 55.6 & 35.4 \\
\hline
\end{tabular}


Table 4 - Test Conditions summary for Fig. 5 (b)

$V_{D D}=800 \mathrm{~V} ; T_{C A S E}=150^{\circ} \mathrm{C} ; E_{A V}=1.2 \mathrm{~J}$

\begin{tabular}{|c|l|l|l|l|l|}
\hline \# & $\boldsymbol{I o}(\boldsymbol{A})$ & $\boldsymbol{L}(\boldsymbol{u H})$ & $\boldsymbol{V}_{\boldsymbol{B D}(\text { eff })}(\boldsymbol{V})$ & ton $($ us $)$ & $\boldsymbol{t}_{\boldsymbol{A V}}($ us $)$ \\
\hline 1 & 23.4 & 2607 & 1874 & 95.2 & 56.8 \\
\hline 2 & 25.3 & 2282 & 1885 & 84.8 & 53.2 \\
\hline $\mathbf{3}$ & $\mathbf{2 8 . 2}$ & $\mathbf{1 8 4 4}$ & $\mathbf{1 8 8 8}$ & $\mathbf{8 0 . 1}$ & $\mathbf{4 7 . 8}$ \\
\hline
\end{tabular}

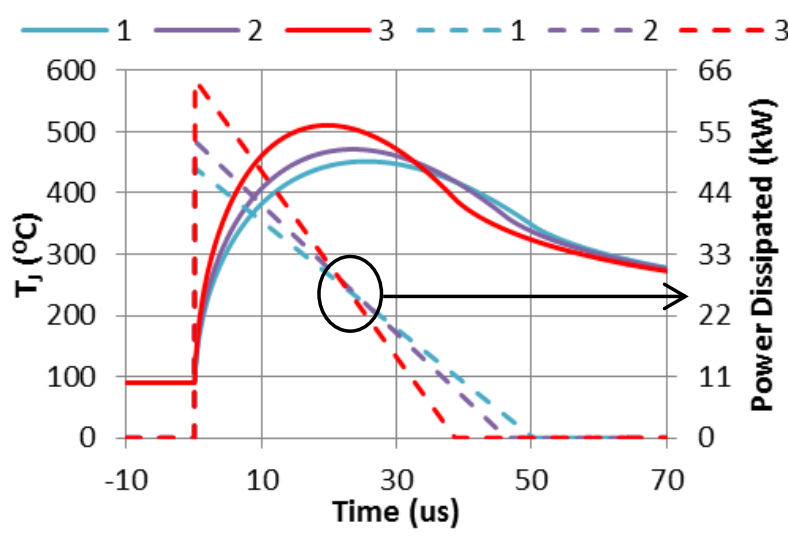

Fig. 6. Simulation of Junction temperature for test conditions from Table 1 at $V_{D D}=400 \mathrm{~V}$.

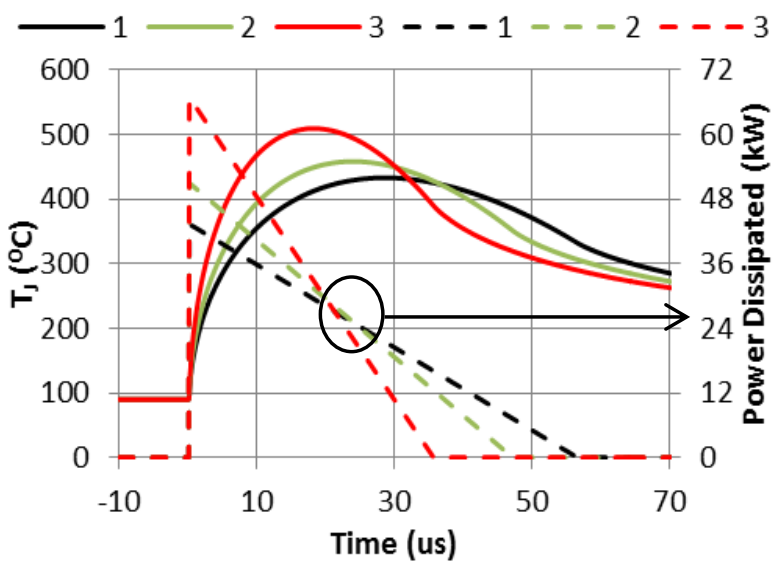

Fig. 7. Simulation of Junction temperature for test conditions from Table 3 at $V_{D D}=800 \mathrm{~V}$.

The $\mathrm{T}_{\mathrm{J}}$ simulations in PSpice (solid lines) for tests at $90^{\circ} \mathrm{C}$ at $400 \mathrm{~V}$ and $800 \mathrm{~V}$ are included in Fig. 6 and 7 respectively to illustrate the critical $\mathrm{T}_{\mathrm{J}}$ reached at failure. A physics-based 1-D compact equivalent circuit usually used for analysis of short transients in semiconductor chips was implemented for modelling the thermal performance of the device (see [7], for instance). The simulated critical $\mathrm{T}_{\mathrm{J}}$ at failure test conditions for $400 \mathrm{~V}$ and $800 \mathrm{~V}$ is $511^{\circ} \mathrm{C}$ and $510^{\circ} \mathrm{C}$ respectively. A more detailed study on single-pulse transient UIS tests can be found in [4], [8]. Preliminary thermal maps showing temperature distribution in the chip $(3.1 \times 3.1 \mathrm{~mm})$ before failure are included in the next section. A more detailed thermal measurement study is still needed before a conclusive explanation could be provided behind the cause of failure.

\subsection{Transient IR thermal measurements}

In order to detect information regarding the temperature distribution during avalanche operation, an ultrafast IR mapping system has been used on bare dies $[9,10]$. Since the experimental set-up uses an equivalent time technique, only two thermal maps were taken at $t_{1}$ and $t_{2}$ (see Fig. 8) during each UIS test to avoid an excessive electro-thermal stress applied to the DUT. Thermal measurements have been carried out during three different UIS tests depicted in Fig. 8. In order to attain quantitative and calibrated information from the radiance data detected by the IR Camera, the emissivity map of the target surface has been evaluated using the "two point calibration" [11]. As a consequence, after a correction algorithm, thermal maps report good estimations of the device surface temperature.

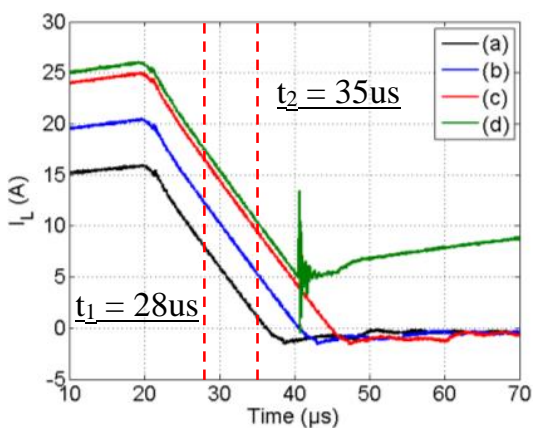

(A)

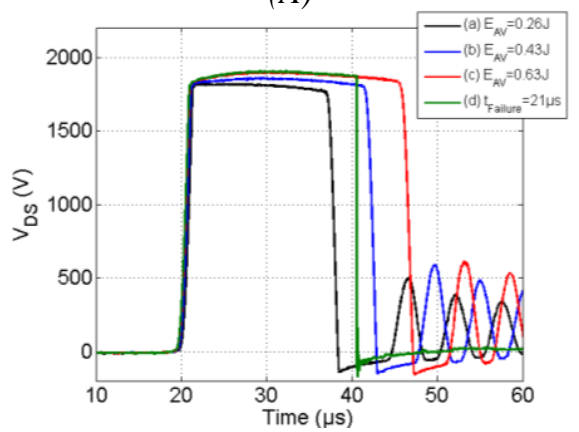

(B)

Fig. 8. UIS electrical waveforms: (A) $I_{L}$ and (B) $V_{D S}$, with $T_{C A S E}=27^{\circ} \mathrm{C} ; \mathrm{L}=1.8 \mathrm{mH}$; (a) $V_{D D}=140 \mathrm{~V}$, $t_{O N}=$ $200 u s$ (b) $V_{D D}=180 \mathrm{~V}, t_{O N}=200 u s$ (c) $V_{D D}=200 \mathrm{~V}$, $t_{O N}=220 u s ;(d) V_{D D}=200 \mathrm{~V}, t_{O N}=230 u s$. 


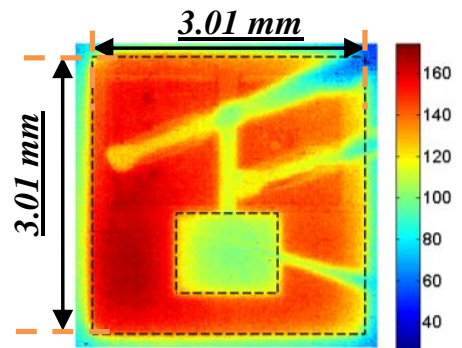

$\left(\mathrm{a}-\mathrm{t}_{1}\right)$

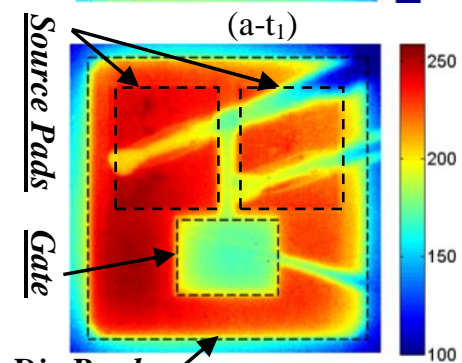

Die Border $\left(\mathrm{b}-\mathrm{t}_{1}\right)$

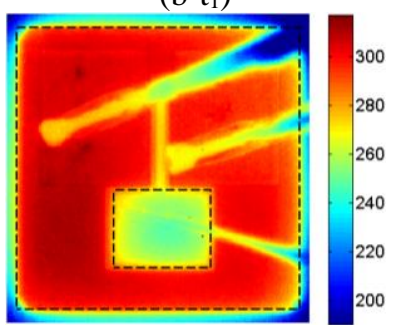

$\left(\mathrm{c}-\mathrm{t}_{1}\right)$

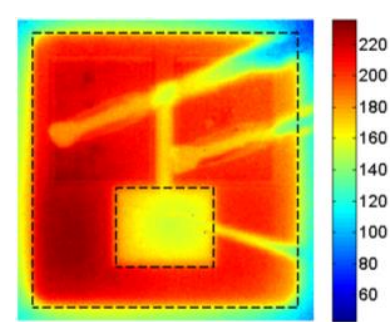

$\left(\mathrm{a}-\mathrm{t}_{2}\right)$

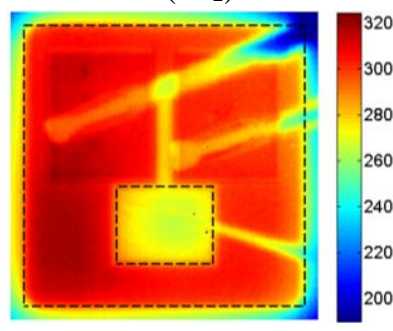

$\left(b-t_{2}\right)$

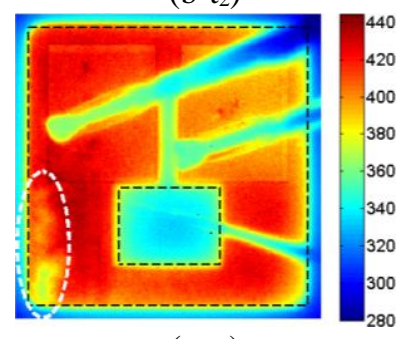

$\left(\mathrm{c}-\mathrm{t}_{2}\right)$

Fig. 9. Thermal maps taken during UIS tests of Fig.

8. The time instants are $t_{1}=28 \mathrm{us}, t_{2}=35 \mathrm{us}$.

During each tests, $\mathrm{T}_{\mathrm{CASE}}$ has been fixed to $27^{\circ} \mathrm{C}$. Referring to Fig. 9, in the first case (a) the device reached a maximum temperature of $225^{\circ} \mathrm{C}$; the temperature distribution evidences a non-uniformly distributed avalanche current, with hottest area situated in the lower-left corner. In case (b) and (c), the temperature maps show peak temperatures of about $320^{\circ} \mathrm{C}$ and $442^{\circ} \mathrm{C}$ respectively. In the last thermal measurement, IR maps show that: (i) at time $t_{1}$ the temperature distribution is quite uniform with a hottest point in the lower-left corner near the termination area (ii) at time $t_{2}$, the DUT undergoes a structural damage at the hottest point. This affirmation is based on the observation of an uneven temperature decrease just close to the previous hottest point.

Thermal maps in Fig. 9 for test conditions just before failure indicate damage to some cells in the lower-left corner of the chip and thus they are not conducting as much current as the other cells are and thus the reason for the temperature drop (dotted line). The simulated critical $\mathrm{T}_{\mathrm{J}}$ was $510^{\circ} \mathrm{C}$ and $511^{\circ} \mathrm{C}$ for 2 different test conditions for the same $\mathrm{E}_{\mathrm{AV}}$ but different

$V_{D D}$ which correlates to the chip temperature of $442^{\circ} \mathrm{C}$ just before failure. The chip temperature and simulation $T_{J}$ are quite close to each other and hence it is confirmed that the failure occurs when the critical $T_{J}$ is reached inside the device as opposed to the failures seen in $\mathrm{Si}$ where the failures were caused due to the physics of the device. This is also an indication of the added robustness that could be achieved in $\mathrm{SiC}$ MOSFETs if structural related issues are addressed to fully utilize the capabilities of SiC WBG material.

\subsection{Ageing test}

For the ageing test, the device was subjected to a repeated dissipation of constant $\mathrm{E}_{\mathrm{Av}}$ level well below its nominal maximum rating. This test was carried out at a fixed $\mathrm{V}_{\mathrm{DD}}$ of $400 \mathrm{~V}$ and $\mathrm{T}_{\mathrm{CASE}}$ of $150^{\circ} \mathrm{C}$. The delay between the pulses was set to $2 \mathrm{~s}$ to allow the device to cool down. The device was turned $\mathrm{OFF}$ at $\mathrm{I}_{\mathrm{AV}}$ of $35 \mathrm{~A}$ with a $t_{A v}$ of $22 u s$ which equalled to about $E_{A v}=0.7 \mathrm{~J}$. In order to monitor the changes in device characteristics, two parameters named the gate threshold voltage $\left(\mathrm{V}_{\text {th }}\right)$ and body diode forward voltage $\left(\mathrm{V}_{\mathrm{f}}\right)$ were measured at regular intervals. All of these parameters show a marked deviation from the initial value, already after few thousand pulses. A total of $669 \mathrm{k}$ pulses were sent to the device and all the measurements obtained for $\mathrm{V}_{\text {th }}$ and $\mathrm{V}_{\mathrm{f}}$ differ from the previous ones which demonstrates continuous degradation taken place in the device.

For this particular investigation, $\mathrm{V}_{\text {th }}$ is defined as the gate-source voltage when the drain current is equal to $5 \mathrm{~mA}$. Fig. 10 shows the evolution of gate-source $\mathrm{V}_{\mathrm{TH}}$ when subjected to a repetitive $\mathrm{E}_{\mathrm{AV}}$ of $0.7 \mathrm{~J}$ at $\mathrm{T}_{\mathrm{CASE}}$ of $150^{\circ} \mathrm{C}$, which highlights a considerable degradation of the device characteristics.

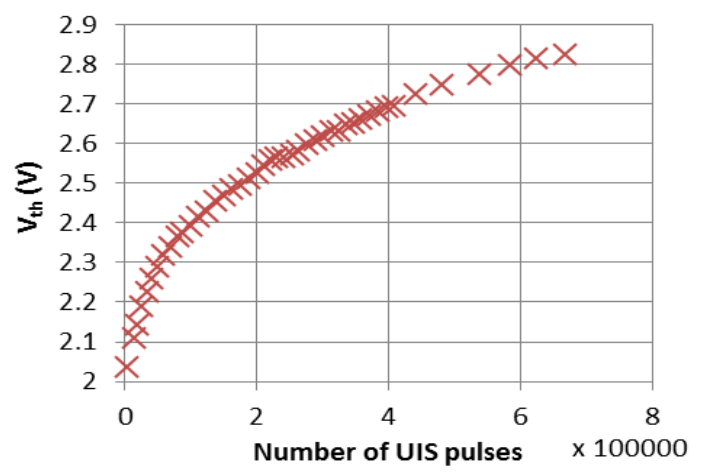

Fig. 10. Evolution of gate-source threshold voltage $\left(V_{t h}\right)$ as a result of repetitive UIS stress

Fig. 10 shows that the $\mathrm{V}_{\mathrm{TH}}$ has a positive shift as the number of UIS pulses increase. The shift of the $\mathrm{V}_{\mathrm{TH}}$ is 
due to the interfacial charge (electrons for n-channel) trapped at and near the $\mathrm{SiO}_{2}-\mathrm{SiC}$ interface and therefore leads to a significant degradation of the device performance by not only reducing the effective channel mobility considerably but also by shifting the threshold voltage [12].

The $\mathrm{V}_{\mathrm{TH}}$ instability of $\mathrm{SiC}$ power MOSFETs is an ongoing area of research and previous studies show that the $\mathrm{V}_{\text {th }}$ instability can be reduced by applying a nitric oxide $(\mathrm{NO})$ or nitrous oxide $\left(\mathrm{N}_{2} \mathrm{O}\right)$ postoxidation anneal during the device manufacturing stage. Improvement of $\mathrm{V}_{\mathrm{TH}}$ stability is a major requirement in the development of technologically matured $\mathrm{SiC}$ power MOSFETs to allow power electronics circuitry solely based on SiC devices [12,13].

Power MOSFETs have a parasitic body diode which consists of the source-drain p-n junction. Fig. 11 shows how the $\mathrm{V}_{\mathrm{f}}$ changed during the test. During the avalanche event, the current flows through the body diode of the device and hence this quantity gives an indication of the impact that repetitive avalanche stress had on the body diode.

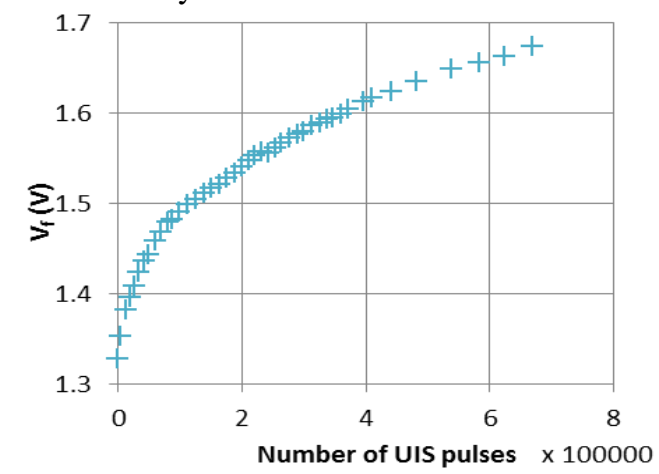

Fig. 11. Evolution of body diode forward voltage

$\left(V_{f}\right)$ as a result of repetitve UIS stress

The body diode $\mathrm{V}_{\mathrm{f}}$ of the SiC MOSFET also has a positive shift as the number of UIS pulses increase. The basal plane dislocations present in the substrate and epilayers give rise to the growth of stacking faults. The growth of stacking faults sufficiently kill the lifetime of minority carriers which effectively prevent conduction modulation through them and therefore results in an increase of $V_{f}$. Manufacturers have encountered this problem in the past and found that improvements in the growth process of thick epitaxial layer using hot wall chemical vapor deposition (CVD) results in reduction of the density of basal plane defects in the blocking layer of the device which has allowed large area power diodes with no $\mathrm{V}_{\mathrm{F}}$ degradation [14].

\section{Conclusions}

This paper presented a detailed functional as well as structural characterisation of state of the art commercial $1200 \mathrm{~V}$ SiC power MOSFETs under singlepulse and repetitive UIS test conditions to demonstrate robustness and avalanche ruggedness. The single pulse robustness test show that not only the $\mathrm{E}_{\mathrm{Av}}$ but also the rate of power dissipation plays a role in determination of avalanche failure. The thermal maps are comparable with the $\mathrm{T}_{\mathrm{J}}$ simulation confirming that the failure is related to critical $\mathrm{T}_{\mathrm{J}}$ being reached inside the chip and as a result some cells are damaged. The repetitive results show a continuous degradation of the device characteristics. The results show that SiC MOSFETs have a sufficient level of robustness which is hindered by the structure and packaging related issues which need to be further researched upon in order to allow a step forward towards the development of robust and reliable power systems based on SiC devices.

\section{References}

[1] - Treu, M.; Rupp, R.; Solkner, G., "Reliability of SiC power devices and its influence on their commercialization - review, status, and remaining issues," Reliability Physics Symposium (IRPS), 2010 IEEE International, vol., no., pp. 156, 161, 2-6 May 2010

[2] - Rabkowski, J.; Peftitsis, D.; Nee, H-P, "Silicon Carbide Power Transistors: A New Era in Power Electronics Is Initiated," Industrial Electronics Magazine, IEEE, vol. 6 , no. 2, pp. 17, 26, June 2012

[3] - Fischer, K.; Shenai, K., "Dynamics of power MOSFET switching under unclamped inductive loading conditions," Electron Devices, IEEE Transactions on, vol. 43, no. 6, pp. 1007, 1015, June 1996

[4] - Fayyaz, A.; Yang, L : Castellazzi, A., "Transient robustness testing of silicon carbide (SiC) power MOSFETs," Power Electronics and Applications (EPE), 2013 15th European Conference on, vol., no., pp. 1, 10, 2-6 Sept. 2013

[5] - Castellazzi, A.; Honsberg-Riedl, M.; Wachutka, G., "Thermal characterisation of power devices during transient operation," Microelectronics Journal 37 (2), 145 151,2006

[6] - Blackburn, D.L., "Power MOSFET failure revisited," Power Electronics Specialists Conference, 1988. PESC '88 Record., 19th Annual IEEE, vol. 2, no., pp. 681, 688, 11-14 April 1988

[7] - Castellazzi, A.; Ciappa, M.; Fichtner, W.; Lourdel, G.; Mermet-Guyennet, M.; "Compact modelling and analysis of power-sharing unbalances in IGBT-modules used in traction applications," Microelectronics Reliability, 2006

[8] - Yang, L.; Fayyaz, A.; Castellazzi, A., "Characterization of High-Voltage SiC MOSFETs under UIS Avalanche Stress," Power Electronics, Machines and Drives (PEMD), 2014 7th IET International conference on, vol., 8-10 April 2014

[9] - Riccio, M.; Castellazzi, A.; De Falco, G.; Irace, A., "Experimental analysis of electro-thermal instability in SiC Power MOSFETs," Microelectronics Reliability Journal 53 (9-11), 1739-1744

[10] - Riccio, M.; Breglio G.; Irace A.; Spirito P., "An equivalent-time temperature mapping system with a 320256 pixels full-frame $100 \mathrm{kHz}$ sampling rate," Rev Sci Instrum 2007

[11] - Riccio, M.; Pantellini, A.; Irace, A.; Breglio, G.; Nanni, A.; Lanzieri, C., "Electro-thermal characterization of AlGaN/GaN HEMT on Silicon Microstrip Technology", Microelectronics Reliability, vol. 51, no. 9-11, pp. 1725-1729, SepNov 2011

[12] - Lelis, A.J.; Habersat, D.; Green, R.; Ogunniyi, A.; Gurfinkel, M.; Suehle, J.; Goldsman, N., "Time Dependence of Bias-Stress-Induced SiC MOSFET ThresholdVoltage Instability Measurements," Electron Devices, IEEE Transactions on, vol.55, no.8, pp.1835,1840, Aug. 2008

no.8, pp.1835,1840, Aug. 2008
[13] - Gurfinkel, M.; Xiong, H. D.; Cheung, K. P.; Suehle, J. S.; Bernstein, J. B.; Shapira, Y.; Lelis, A. J.; Habersat, D.; Goldsman, N., "Characterization of Transient Gate Oxide Trapping in SiC MOSFETs Using Fast I-V Techniques," Electron Devices, IEEE Transactions on, vol. 55, no. 8, pp. 2004, 2012, Aug. 2008

[14] - Palmour, J. W.; Agarwal, A.; Ryu, S.-H.; Das. M.; Sumakeris, J.; Powell, A., "Large Area Silicon Carbide Power Devices on 3 inch wafers and Beyond," CS MANTECH Technical Digest, 2005 pp. 229 - 232, April 2005 